\section{Cosmic dust in the earth's atmosphere $\dagger$}

\author{
John M. C. Plane* \\ Received 8th April 2012 \\ DOI: $10.1039 / \mathrm{c} 2 \mathrm{cs} 35132 \mathrm{c}$
}

This review discusses the magnitude of the cosmic dust input into the earth's atmosphere, and the resulting impacts from around $100 \mathrm{~km}$ to the earth's surface. Zodiacal cloud observations and measurements made with a spaceborne dust detector indicate a daily mass input of interplanetary dust particles ranging from 100 to 300 tonnes, which is in agreement with the accumulation rates of cosmic-enriched elements (Ir, Pt, Os and super-paramagnetic Fe) in polar ice cores and deep-sea sediments. In contrast, measurements in the middle atmosphere - by radar, lidar, high-flying aircraft and satellite remote sensing - indicate that the input is between 5 and 50 tonnes per day. There are two reasons why this huge discrepancy matters. First, if the upper range of estimates is correct, then vertical transport in the middle atmosphere must be considerably faster than generally believed; whereas if the lower range is correct, then our understanding of dust evolution in the solar system, and transport from the middle atmosphere to the surface, will need substantial revision. Second, cosmic dust particles enter the atmosphere at high speeds and undergo significant ablation. The resulting metals injected into the atmosphere are involved in a diverse range of phenomena, including: the formation of layers of metal atoms and ions; the nucleation of noctilucent clouds, which are a sensitive marker of climate change; impacts on stratospheric aerosols and $\mathrm{O}_{3}$ chemistry, which need to be considered against the background of a cooling stratosphere and geo-engineering plans to increase sulphate aerosol; and fertilization of the ocean with bio-available Fe, which has potential climate feedbacks.

\section{Introduction}

The solar system is full of dust: if all the dust in the inner solar system (i.e. between the sun and Jupiter) were compressed

School of Chemistry, University of Leeds, Woodhouse Lane,

Leeds LS2 9JT, U.K. E-mail: j.m.c.plane@leeds.ac.uk;

Fax: 44113343 6401; Tel: 441133438044

$\dagger$ Part of the atmospheric chemistry themed issue.

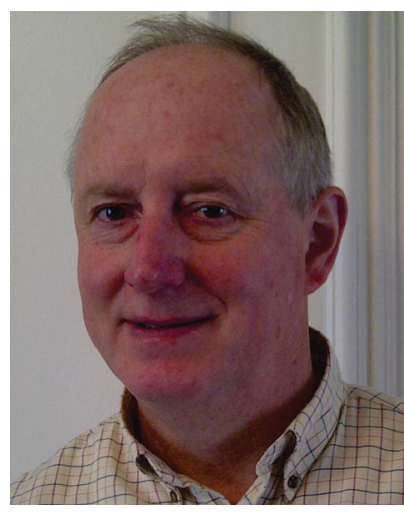

John M. C. Plane
Following his PhD in physical chemistry at Cambridge University (1983), John Plane was a Research Fellow at St. John's College and then Associate Professor at the Rosenstiel School of Marine and Atmospheric Science (University of Miami, Florida). He moved to the University of East Anglia (1991), becoming Professor of Environmental Science in 1999. Since 2006 he has been Professor of Atmospheric Chemistry at the University of Leeds. together it would form a moon $25 \mathrm{~km}$ in diameter. ${ }^{1}$ The main sources of dust are collisions between asteroids (the asteroid belt lies between the orbits of Mars and Jupiter), and the sublimation of comets (which are balls of dust-laden ice) as they approach the sun on their orbits through the solar system. ${ }^{2,3}$ Fresh dust trails produced by comets which crossed the earth's orbit recently (within the last 100 years or so) are the origin of meteor showers such as the Perseids and Leonids. ${ }^{4}$ Dust particles from long-decayed cometary trails and the asteroid belt give rise to a continuous input of sporadic meteoroids, which provides a much greater mass flux on average than meteor showers., ${ }^{2,3}$

This review addresses an apparently simple question: what is the magnitude of the cosmic dust input to the earth's atmosphere? Table 1 shows that even very recent estimates of the Interplanetary Dust Particle (IDP) input vary from 5 to $270 \mathrm{t} \mathrm{d}^{-1}$ (tonnes per day). Zodiacal cloud observations and spaceborne dust detection (dark blue shading in Table 1) indicate a daily input of $100-300 \mathrm{t} \mathrm{d}^{-1}$, which is mostly in agreement with the accumulation rates of cosmic elements in polar ice cores and deep-sea sediments (grey shading). In contrast, measurements in the middle atmosphere (light blue shading) - by radar, lidar, high-flying aircraft and satellite remote sensing - indicate that the input is only 5-50 tonnes.

There are two reasons why this matters. First, if the upper range of estimates is correct, then vertical transport in 
Table 1 Estimates of the global IDP input rate to the Earth's atmosphere (deep blue = extra-terrestrial estimate; light blue = middle atmosphere estimate; grey = ice core/deep-sea estimate)

\begin{tabular}{|c|c|c|c|}
\hline Technique & IDP input $t^{d^{-1}}$ & Reference & Potential problem of technique \\
\hline $\begin{array}{l}\text { Zodiacal dust cloud observations and } \\
\text { modelling }\end{array}$ & 270 & Nesvorný et al. ${ }^{1}$ & $\begin{array}{l}\text { Needs to be constrained by terrestrial meteor } \\
\text { radars }\end{array}$ \\
\hline Long Duration Exposure Facility & $110 \pm 55$ & Love \& Brownlee 9 & Sensitive to IDP velocity distribution \\
\hline High performance radars & $5 \pm 2$ & Mathews et al. ${ }^{10}$ & Possible velocity bias / selective mass range \\
\hline Conventional meteor radars & 44 & Hughes $^{11}$ & Extrapolation, selective mass/velocity range \\
\hline Na layer modelling & $20 \pm 10$ & Plane $^{12}$ & Sensitive to vertical eddy diffusion transport \\
\hline Fe layer modelling & 6 & Gardner et al. ${ }^{13}$ & Depends on vertical transport \\
\hline $\mathrm{Fe} / \mathrm{Mg}$ in stratos. sulphate layer & $22-104$ & Cziczo et al. ${ }^{14}$ & Data has limited geographic extent \\
\hline Optical extinction measurements & $10-40$ & Hervig et al. ${ }^{15}$ & Particle refractive indices undertain \\
\hline $\mathrm{Fe}$ in Antarctic ice core & $15 \pm 5$ & Lanci et al. ${ }^{16}$ & Very little wet deposition by snow \\
\hline $\mathrm{Fe}$ in Greenland ice core & $175 \pm 68$ & Lanci \& $\mathrm{Kent}^{17}$ & Uncertain atmospheric transport/deposition \\
\hline Ir and Pt in Greenland ice core & $214 \pm 82$ & Gabrielli et al. ${ }^{18}$ & Uncertain atmospheric transport/deposition \\
\hline Os in deep-sea sediments & $101 \pm 36$ & Peuker-Ehrenbrink $^{19}$ & Focusing by ocean currents \\
\hline Ir in deep-sea sediments & 240 & Wasson \& $\mathrm{Kyte}^{20}$ & Focusing by ocean currents \\
\hline
\end{tabular}

the middle atmosphere must be considerably faster than is generally thought to be the case, so that meteoritic material is removed more rapidly from the atmosphere in order to sustain a higher rate of injection; whereas if the lower range is correct, then our understanding of dust evolution in the solar system, and transport mechanisms from the middle atmosphere to the earth's surface, will need substantial revision. Second, cosmic dust particles enter the atmosphere at high speeds $\left(11-72 \mathrm{~km} \mathrm{~s}^{-1}\right)$ and in most cases completely ablate. ${ }^{5}$ The resulting metals injected into the atmosphere are involved in a diverse range of impacts, including the formation of layers of metal atoms and ions, ${ }^{6}$ nucleation of noctilucent clouds, ${ }^{7}$ effects on stratospheric aerosols and $\mathrm{O}_{3}$ chemistry, and fertilization of the ocean with bio-available $\mathrm{Fe} .^{8}$ These impacts of meteoric ablation obviously depend on the magnitude of the IDP input.

Although the actual measurements in Table 1 appear to be sound, their interpretation to yield the estimated IDP input is potentially compromised by significant uncertainties (final column of Table 1) which are discussed in detail below. The enormous range of values in Table 1 implies a fundamental lack of understanding in at least some parts of the system. In fact, the range is so large that even if the true input is in the "middle" $\left(\sim 20-50 \mathrm{t} \mathrm{d}^{-1}\right)$, significant reassessment of many of these processes will be required.

In this review, the different ways of estimating the IDP input and assessing its impact are grouped into five Science Topics (STs), illustrated in Fig. 1. Moving downwards from the top of the atmosphere, these topics are: the source of IDPs in the inner solar system and the process of meteoric ablation (ST1); the layers of metal atoms and ions which result from ablation (ST2); the formation of meteoric smoke particles and their role as ice nuclei in the mesosphere (ST3); the impacts of meteoric smoke on aerosols and $\mathrm{O}_{3}$ chemistry in the stratosphere (ST4); and the deposition of smoke to the earth's surface (ST5). Fig. 1 illustrates the relationship between these STs. Each ST (grey shaded box) contains phenomena in the Earth System

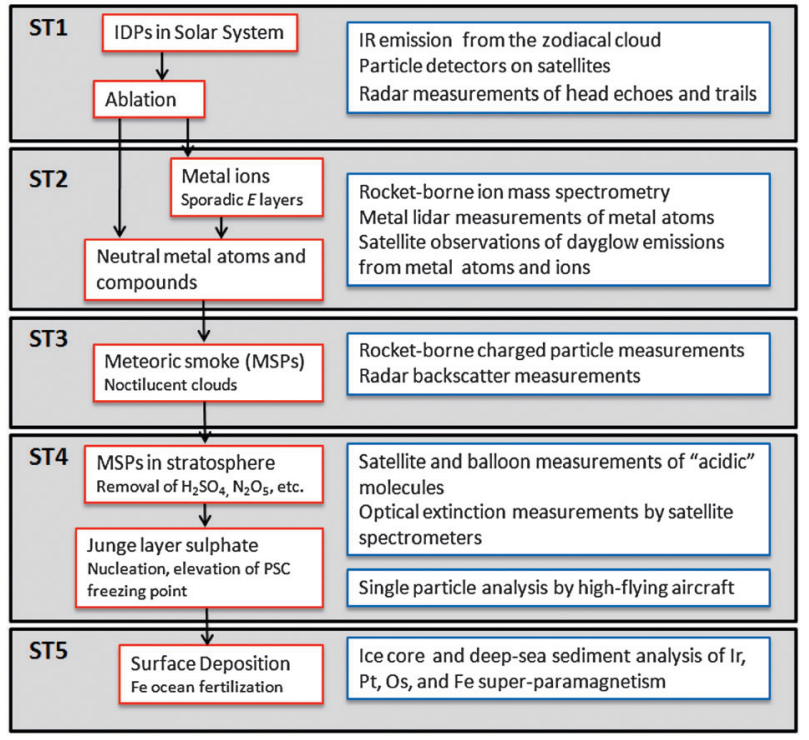

Fig. 1 Structure of the review material, grouped into five Science Topics. Each topic (grey shaded box) contains phenomena in the Earth System (red boxes) which provide an estimate of the IDP input through relevant observations (blue boxes).

(red boxes) which provide an estimate of the IDP input through relevant observations (blue boxes). Note that a list of acronyms appears at the end of the review.

\section{ST1. IDPs in the solar system and meteoric ablation}

Zodiacal light is the very faint diffuse glow caused by sunlight scattering off the zodiacal cloud. This cloud consists of IDPs concentrated close to the ecliptic (i.e., the plane containing the sun and orbits of the planets). A recent Zodiacal Cloud Model $(\mathrm{ZCM})^{1}$ starts with the orbital properties of comets and asteroids and then follows the dynamical evolution of dust 
particles after ejection from these sources. The model is constrained by observations of the zodiacal cloud in the infrared at $25 \mu \mathrm{m}$, made by the Infrared Astronomical Satellite (IRAS). The ZCM predicts that $85-95 \%$ of the dust in the inner solar system comes from Jupiter family comets, which are comets with short orbital periods (typically 20 years) and an aphelion close to the orbit of Jupiter. The remaining dust comes from the asteroid belt and Halley family and Oort cloud comets. Most of the dust, which drifts into the inner solar system under the influence of Poynting-Robertson drag (solar photon pressure, which causes the orbital velocities of IDPs with a radius larger than $\sim 1 \mu \mathrm{m}$ to decelerate), has a mass in the range $1-10 \mu \mathrm{g}$ and provides a continuous input of sporadic meteoroids. The model predicts that these IDPs should enter the terrestrial atmosphere from a near-prograde orbit with a mean speed of $\sim 14 \mathrm{~km} \mathrm{~s}^{-1}$, producing a global mass input around $270 \mathrm{t} \mathrm{d}^{-1}$, the highest estimate in Table 1 .

The input flux of meteoroids into the atmosphere is so uncertain because no single technique can observe particles over the mass range from about $10^{-12}$ to $1 \mathrm{~g}$ which make up the bulk of the incoming material. ${ }^{3}$ Fig. 2 shows that the particle mass can vary by 30 orders of magnitude, although the largest contribution of mass entering the atmosphere on a daily basis comes from particles around $10 \mu \mathrm{g}$. Assuming a meteoroid density of $\sim 2.8 \mathrm{~g} \mathrm{~cm}^{-3}$, these particles will have a diameter of $\sim 200 \mu \mathrm{m}$. There is a population of huge impactors with masses greater than $10^{10} \mathrm{~g}$ which make a significant contribution, but only on a geological timescale! Any single measurement technique will only sample a subset of this size distribution. For instance, optical camera networks which observe visible meteors detect particles larger than about $1 \mathrm{mg}$ in mass, or $1 \mathrm{~mm}$ in radius. Larger particles (approaching $1 \mathrm{~g}$ in mass) are much rarer, so that counting statistics on a time scale of months start to matter.

Meteor radars measure particles with masses between about $10^{-9}$ and $10^{-3} \mathrm{~g}$, and therefore cover the most important mass range (Fig. 2). Meteor radar data was used to produce a muchquoted estimate of $44 \mathrm{t} \mathrm{d}^{-1}$ for the global input, although this involved artificially increasing the size distribution to match visual meteor observations. ${ }^{11}$ The evaporating atoms, particularly metals,

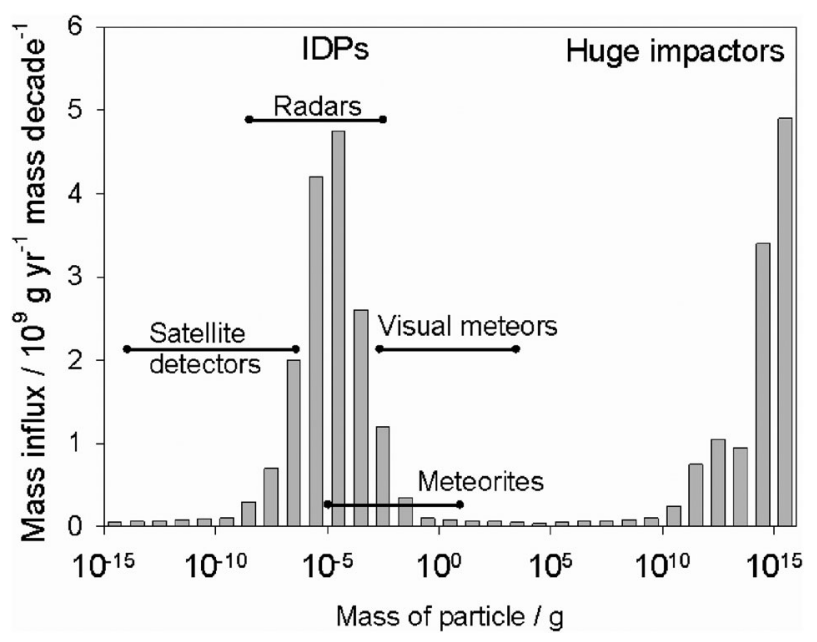

Fig. 2 Mass influx (per decade of mass) plotted against particle mass [data taken from Flynn ${ }^{21}$ ]. ionize through hyperthermal collisions with air molecules. ${ }^{5}$ This creates a trail of electrons behind the meteoroid, which can be detected by radar. The mass and speed of the meteoroid then have to be estimated indirectly. ${ }^{22}$ Furthermore, the wavelength of the radar only samples a subset of the mass/ velocity/altitude distribution of the meteoroids, so that some extrapolation is required to estimate the total mass input. ${ }^{11}$

In the past two decades, high-powered large aperture (HPLA) radars, such as the Arecibo Observatory and the EISCAT radars in the Arctic, have been able to detect by incoherent scatter the meteor head echo (i.e. the ball of plasma around the ablating particle as it descends through the atmosphere). This enables measurements of the direction of origin, velocity, deceleration and (indirectly) mass to be made..$^{10,23-25}$ While initially the mean entry velocity seemed to be significantly higher, around $40-50 \mathrm{~km} \mathrm{~s}^{-1}$, than the velocity measured with conventional meteor radars, it has now been realised that there is a sampling bias towards high-speed meteors. ${ }^{26}$ Conventional meteor radars do not efficiently detect meteors which occur at higher altitudes $(>100 \mathrm{~km})$, because of the rapid diffusion of the ionized trails. Since faster meteors generally occur at higher altitudes, distributions measured by meteor radars are biased towards the lower speeds. In fact, it has now been shown ${ }^{27}$ that HPLA radars observe the same population of meteors as observed by meteor radars, and in addition detect a population of faster meteors that ablate at altitudes where trails are not efficiently detected. However, the magnitude of the head echo still depends on the meteoroid mass and velocity, and each HPLA radar is sensitive to a particular mass range. ${ }^{27}$ This implies that the velocity distribution of the smallest particles measured by an HPLA radar will be biased towards faster speeds: small and slow particles will not have sufficient kinetic energy to ablate, and hence will not produce sufficient electrons to be detected. The average entry speeds are now thought to be between 25 and $30 \mathrm{~km} \mathrm{~s}^{-1}$. ${ }^{28}$ It should be noted that particles which originate within the solar system must have entry velocities that range from $11.5 \mathrm{~km} \mathrm{~s}^{-1}$ for a particle in the same prograde orbit as the Earth (i.e. orbiting in the same direction), to $72 \mathrm{~km} \mathrm{~s}^{-1}$ for a particle in a retrograde orbit. $^{2}$

The population of IDPs smaller than $10^{-9} \mathrm{~g}$ can only be measured by impact detectors on satellites. An important estimate of the IDP input was provided by the Long Duration Exposure Facility (LDEF), an orbital impact detector placed on a spacecraft for several years, which yielded an estimate of $110 \mathrm{t} \mathrm{d}^{-1}$. ${ }^{9}$ However, the LDEF experiment measured crater size, which was treated as a proxy for particle kinetic energy. Hence, the particle velocity distribution had to be assumed in order to determine the mass distribution. If the average velocity is higher (see above) than the value of only $18 \mathrm{~km} \mathrm{~s}^{-1}$ that was employed in the LDEF analysis, then the corresponding mass distribution would be shifted down by more than an order of magnitude. ${ }^{10}$

Because of their very high entry velocities, meteoroids undergo rapid frictional heating by collision with air molecules. If the particles reach melting point $(\sim 1800 \mathrm{~K})$, their constituent minerals will then rapidly vaporize - the process termed meteoric ablation. Ablation tends to occur where the atmospheric pressure is around $1 \mu \mathrm{bar}$. In the case of the Earth, 
the peak ablation rate is around $90 \mathrm{~km}$, compared with $80 \mathrm{~km}$ on Mars, $115 \mathrm{~km}$ on Venus, and $500 \mathrm{~km}$ on Titan. ${ }^{29}$ The physical chemistry of ablation has been treated in detail by several investigators. ${ }^{30-32}$ The problem becomes manageable for particles smaller than about $250 \mu \mathrm{m}$ in radius, because heat conductivity through the particle is then fast enough for the particle to be treated as isothermal. ${ }^{30}$ Assuming a density of $2.8 \mathrm{~g} \mathrm{~cm}^{-3}$ (typical of an ordinary chondrite), a $250 \mu \mathrm{m}$ meteoroid has a mass of $180 \mu \mathrm{g}$ (which, as Fig. 2 shows, is larger than the bulk of the IDP mass input).

The frictional heating of the meteoroid by collisions with air molecules is balanced by radiative loss and the consumption of heat energy through temperature increase, melting and vaporization. ${ }^{5}$ In order to calculate these terms, parameters such as the meteoroid shape, density, and composition are needed. The question of composition has been discussed in detail recently. ${ }^{33,34}$ There is some uncertainty here because of the great variability in composition of different types of meteorites. ${ }^{33}$ Furthermore, it may be that the composition of the meteoroids that ablate in the upper atmosphere is different from that of the meteorites that have survived transit through the atmosphere. ${ }^{33}$ Nevertheless, the current assumption is that most IDPs have the composition of ordinary chondrites, which is essentially olivine $\left(\mathrm{FeMgSiO}_{4}\right)$. The elemental abundances of the major metallic constituents relative to $\mathrm{Si}(1.0)$ are then: $\mathrm{Mg}(1.07), \mathrm{Fe}(0.90)$, $\mathrm{Al}$ (0.085), $\mathrm{Ca}(0.061), \mathrm{Na}(0.057)$ and $\mathrm{Ni}(0.049) .{ }^{35}$

If the particle is roughly spherical (which should be the case once it has melted), then the energy balance equation is given by: ${ }^{36}$

$$
\frac{1}{2} \pi R^{2} \rho_{\mathrm{a}} v^{3} \Lambda=4 \pi r^{2} \sigma \varepsilon\left(T_{\mathrm{s}}^{4}-T_{\mathrm{a}}^{4}\right)+\frac{4}{3} \pi R^{3} \rho_{\mathrm{m}} C \frac{\mathrm{d} T_{\mathrm{m}}}{\mathrm{d} t}+L \frac{\mathrm{d} m}{\mathrm{~d} t}
$$

The left-hand side of eqn (I) represents the frictional heating term, where $\Lambda$ is the dimensionless heat transfer coefficient (i.e. fraction of the total kinetic energy of the air molecules that is transferred to the meteoroid), $\rho_{\mathrm{a}}$ is the atmospheric density, $R$ is the meteoroid radius and $\nu$ is the meteoroid velocity. The first term on the right-hand side describes the radiative loss, where $\sigma$ is Stefan's constant, $\varepsilon$ is the emissivity of the meteoroid, $T_{\mathrm{s}}$ is the surface temperature of the meteoroid, and $T_{\mathrm{a}}$ is the ambient atmosphere temperature. The second term represents the energy losses due to heat capacity (i.e. phase transitions and heating), where $\rho_{\mathrm{m}}$ the meteoroid density, $C$ the meteoroid specific heat, $T_{\mathrm{m}}$ the mean temperature of the particle, and $t$ is the time. The last term is the heat consumed in the transfer of particle mass into the gas phase, where $L$ is the latent heat of vaporization (or sublimation if the particle has not melted) and $m$ is the meteoroid mass.

The deceleration of the meteoroid is given by

$$
\frac{\mathrm{d} v}{\mathrm{~d} t}=-\frac{\Gamma \rho_{\mathrm{a}} \pi R^{2} v^{2}}{m}
$$

where $\Gamma$ is the atmospheric drag parameter (typically between 0.5 and 1$)$.

Inspection of eqn (I) shows that for very small particles the heat capacity term will be much smaller than the radiative loss term, in which case the meteoroid will not become hot enough to ablate. This is the case for all particles smaller than $10^{-12} \mathrm{~g}$.
A $10^{-10} \mathrm{~g}$ particle must enter the atmosphere at over $40 \mathrm{~km} \mathrm{~s}^{-1}$ in order for its temperature to exceed $1800 \mathrm{~K}$, the temperature at which volatile elements such as $\mathrm{Na}$ begin to evaporate rapidly. All meteoroids larger than $10^{-7} \mathrm{~g}$ should reach this ablation temperature. ${ }^{5}$

Interpreting radar measurements requires a model to predict the evaporation rate and subsequent ionization rate of the elemental constituents during ablation. The most recent example is the Chemical Ablation Model (CABMOD), ${ }^{5}$ which treats the physics and chemistry of ablation by including sputtering by inelastic collisions with air molecules before the meteoroid melts, evaporation of atoms and oxides from the molten particle, and impact ionization of the ablated fragments by hyperthermal collisions with air molecules. Evaporation is based on the assumption of thermodynamic equilibrium within the molten meteoroid and between the particle and the surrounding vapour phase. The thermodynamics are provided by the well-established MAGMA code, ${ }^{37}$ which is based on a fractionation model used by planetary scientists to account for mass loss from the planet Mercury. The loss rate of each element is then calculated by applying Langmuir evaporation, which assumes that the rate of evaporation into a vacuum is equal to the rate of evaporation needed to balance the rate of uptake of a species $i$ in a closed system. The rate of mass release of species $i$ with molecular weight $\mu_{i}$ is given by the Herz-Knudsen equation:

$$
\frac{\mathrm{d} m_{i}}{\mathrm{~d} t}=\gamma p_{i} \sqrt{\frac{\mu_{i}}{2 \pi k_{\mathrm{B}} T}}
$$

where $\gamma$ is the uptake (or sticking) coefficient, equal to the probability that species $i$ is retained on the surface, or within the particle, after collision; and $p_{i}$ is the thermodynamic equilibrium pressure of species $i$ in the gas phase.

Fig. 3 illustrates the elemental injection profiles calculated by CABMOD for a meteoroid entering the atmosphere with the most likely mass and velocity according to LDEF. ${ }^{5}$ The mass loss which occurs above $105 \mathrm{~km}$, when the particle has not yet melted $\left(T_{\mathrm{m}}<1800 \mathrm{~K}\right)$, is due to sputtering. Note that CABMOD predicts differential ablation, i.e. the most volatile elements - Na and $\mathrm{K}$ - ablate first, followed by the main constituents $\mathrm{Fe}, \mathrm{Mg}$ and $\mathrm{Si}$, and finally the most refractory elements such as Ca. CABMOD has been used successfully to model the variation of meteor head echoes with height, using measurements made at the Arecibo Observatory. ${ }^{38}$ However, there are two important caveats. First, much of the thermodynamic data in MAGMA has to be extrapolated to temperatures above $2000 \mathrm{~K}$ from measurements below $1700 \mathrm{~K} .{ }^{37}$ Second, Langmuir evaporation represents an upper limit to the evaporation rate, since evaporation into a vacuum can be significantly slower than into a vapour at equilibrium (because diffusion from the bulk into the surface film can become ratedetermining). For instance, the evaporation coefficient from a molten silicate into vacuum can be much less than 1 for elements such as $\mathrm{Fe}(0.25)$ and $\mathrm{Ca}(0.06),{ }^{39}$ which affects the height in the atmosphere where these elements ablate (and also the heating rate of the meteoroid).

Further work is need to remove these uncertainties in chemical ablation models, so that they can be used to correct 


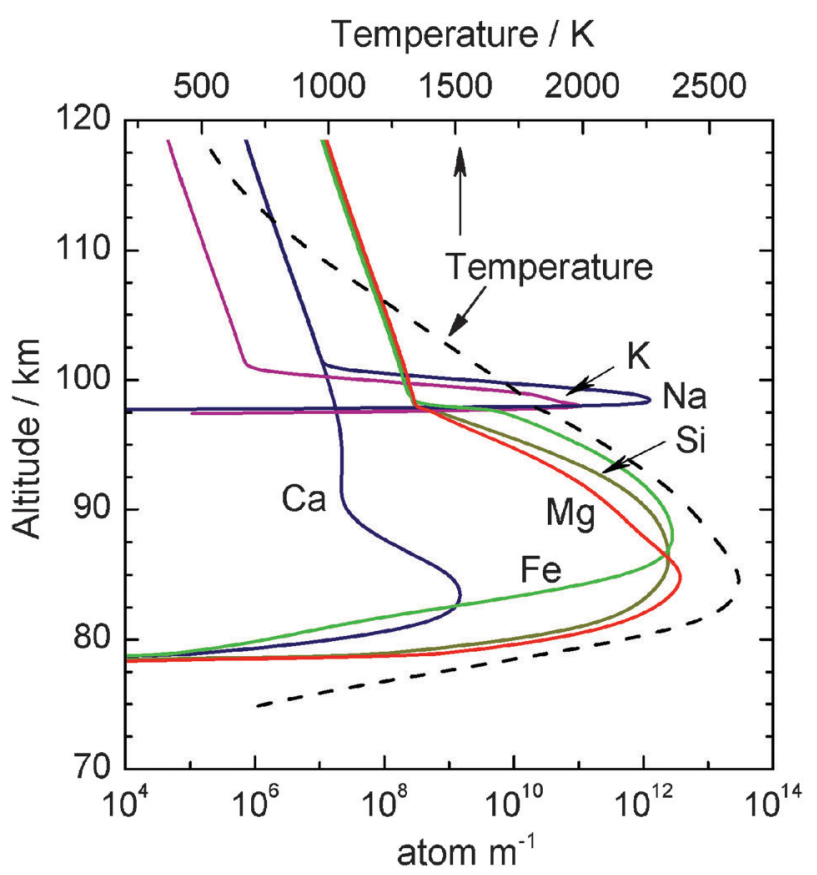

Fig. 3 Elemental ablation profiles for a $5 \mu \mathrm{g}$ meteoroid entering at $20 \mathrm{~km} \mathrm{~s}^{-1}$, as predicted by the Chemical Ablation Model (CABMOD). The particle temperature is shown on the top abscissa.

for biases in the meteor mass/velocity distribution measured by radars. ${ }^{26}$ One important reason for doing this is to refine the ZCM described above, by constraining the predicted IDP orbits and velocities by using radar data. An initial attempt in this direction was published very recently, showing that the IDP input could be reduced to only $41 \mathrm{t} \mathrm{d}^{-1}$ by changing the initial orbital characteristics of IDPs ejected by Jupiter family comets. $^{40}$

\section{ST2. metallic neutral and ion layers}

Ablation produces layers of neutral metal atoms, such as $\mathrm{Fe}$, $\mathrm{Mg}$ and $\mathrm{Na}$, which peak between 85 and $95 \mathrm{~km}$ in the terrestrial atmosphere. ${ }^{6}$ Several of these layers - Na, K, Li, $\mathrm{Ca}, \mathrm{Ca}^{+}$and $\mathrm{Fe}$ - can be observed using ground-based resonance lidars, where the transmitter is tuned to a strongly allowed optical transition (e.g. the $\mathrm{Na}\left({ }^{2} \mathrm{P}_{3 / 2}{ }^{2} \mathrm{~S}_{1 / 2}\right)$ transition at $589.0 \mathrm{~nm}) .{ }^{41}$ Observations can be made continuously over a complete diurnal cycle, provided an astronomical quality telescope and narrow band optical filter are employed for daytime measurements. ${ }^{42}$ One constraint is that the optical transition must be at wavelengths greater than about $300 \mathrm{~nm}$; otherwise, strong absorption by the Hartley band of $\mathrm{O}_{3}$ in the stratospheric ozone layer prevents optical transmission between the ground and the mesosphere, which rules out observations of important metallic species such as $\mathrm{Mg}, \mathrm{Mg}^{+}$ and $\mathrm{Fe}^{+}$.

Lidar observations can be made with extremely good time and height resolution (typically $60 \mathrm{~s}$ and $40 \mathrm{~m}$, respectively, for the Na layer), so that the metal layers can be used as tracers of atmospheric motions such as tides and gravity waves. ${ }^{43}$ In the case of $\mathrm{Na}, \mathrm{K}$ and $\mathrm{Fe}$, a narrow line-width laser can be used in the lidar transmitter to measure temperature and wind profiles in the upper mesosphere. ${ }^{42,44,45}$ This is achieved by scanning the laser across the resonance line to measure the degree of Doppler broadening, and hence the local temperature. By employing a laser with a tuning accuracy and frequency stability of at least $50 \mathrm{MHz}$, the temperature can be measured with an error of $\sim 2 \mathrm{~K}$. The wind along the line-of-sight of the lidar can be determined from the net Doppler shift of the resonance line, typically with an error of less than $3 \mathrm{~m} \mathrm{~s}^{-1}$. By pointing the lidar sequentially in both zenith and off-zenith directions, the wind can then be resolved into the zonal, merional and even vertical components. Another way to measure the temperature is to use a two-colour lidar to measure simultaneously the relative populations of the ${ }^{5} \mathrm{D}_{4}$ and ${ }^{5} \mathrm{D}_{3}$ spin-orbit multiplets of ground-state Fe, from which the temperature can be derived assuming Boltzmann equilibrium. ${ }^{46}$

Metal resonance lidars are thus an extremely important tool for studying the chemistry and physics of the mesosphere/ lower thermosphere (MLT), which is largely inaccessible to direct measurements. High altitude aircraft and research balloons reach altitudes of about 22 and $45 \mathrm{~km}$, respectively, whereas satellites cannot operate below $150 \mathrm{~km}$ without atmospheric drag causing rapid re-entry. The only way to sample the MLT in situ is via rocket-borne payloads. However, because the payload traverses the MLT region at a velocity typically in excess of $1 \mathrm{~km} \mathrm{~s}^{-1}$, the instruments must have a rapid time response. ${ }^{47}$ There have been a number of measurements of the concentrations of positive metallic ions made by rocket-borne mass spectrometry. ${ }^{48,49}$ These flights have been motivated to establish whether there is a link between meteor showers and the abundance of metallic ions (there does not appear to be a significant correlation ${ }^{49}$ ), and the role of metallic ions in forming sporadic $E$ layers and noctilucent clouds $^{48}$ (see ST3).

Metallic ions such as $\mathrm{Mg}^{+}$and $\mathrm{Fe}^{+}$have also been observed by resonant scattering of sunlight, using spectrometers on space vehicles. ${ }^{50}$ More recently, satellite observations have also been made of the neutral $\mathrm{Na}$ and $\mathrm{Mg}$ layers. ${ }^{51-53}$ The vertical resolution achievable with limb-scanning spectrometers on satellites is only about $2 \mathrm{~km}$ ( $c f$. the lidar vertical resolution of $40 \mathrm{~m}$ ), but satellites in polar sun-synchronous orbits provide near-global coverage. Fig. 4 illustrates the Na column abundance (i.e. the concentration of the Na layer integrated over height), as a function of latitude and season. The satellite data-set ${ }^{51}$ has been supplemented with ground-based lidar data during the polar winter when the Na layer is not solar-illuminated. Fig. 4 illustrates that there is very little seasonal variation at low latitudes (less than a factor of 2), but the winter/summer ratio increases to nearly an order of magnitude at high latitudes. The primary reason for the large summertime depletion at high latitudes is the very low temperature during the summer because of the adiabatic cooling of upwelling air. ${ }^{6}$ A secondary reason is the efficient removal of metallic species on noctilucent cloud particles (see ST3). ${ }^{54,55}$

Understanding the characteristic features of the metallic layers in the upper atmosphere has required studying the reaction kinetics of neutral and ionized metallic species with atmospheric constituents such as $\mathrm{O}_{3}, \mathrm{O}_{2}, \mathrm{O}$ and $\mathrm{H}$. Over the past 30 years, the two classical techniques of flash photolysis 


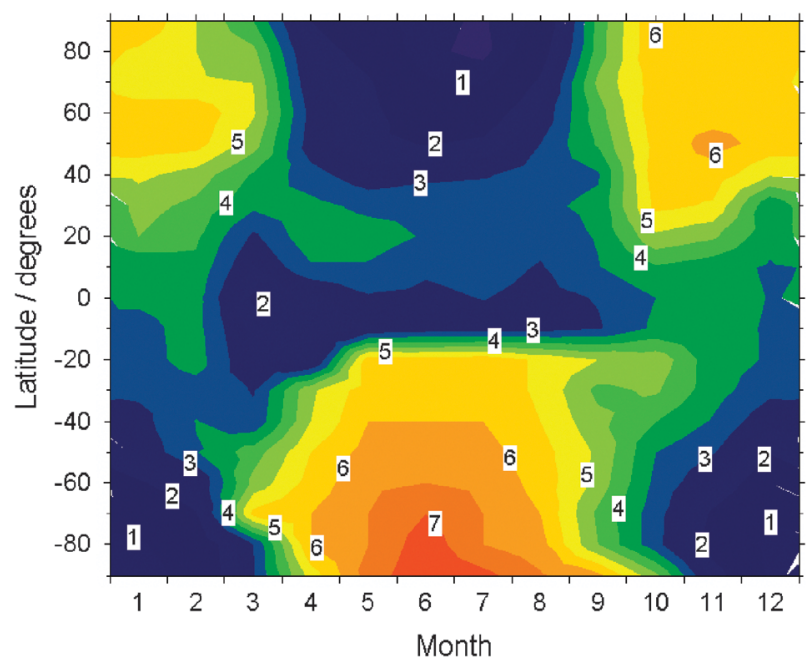

Fig. 4 Column abundance of the Na layer (units: $10^{9}$ atom $\mathrm{cm}^{-2}$ ) as a function of latitude and month.

and the fast flow tube have provided a great deal of kinetic data on the pertinent reactions of the meteoric metals Fe, $\mathrm{Mg}$, $\mathrm{Na}$, Ca and $\mathrm{K} .{ }^{6,41,56}$ The results have been used to construct atmospheric models which successfully explain the metal layers above $80 \mathrm{~km} \cdot{ }^{6,12,13,41,57}$ Fig. 5 illustrates the author's current model of iron chemistry in the upper atmosphere.

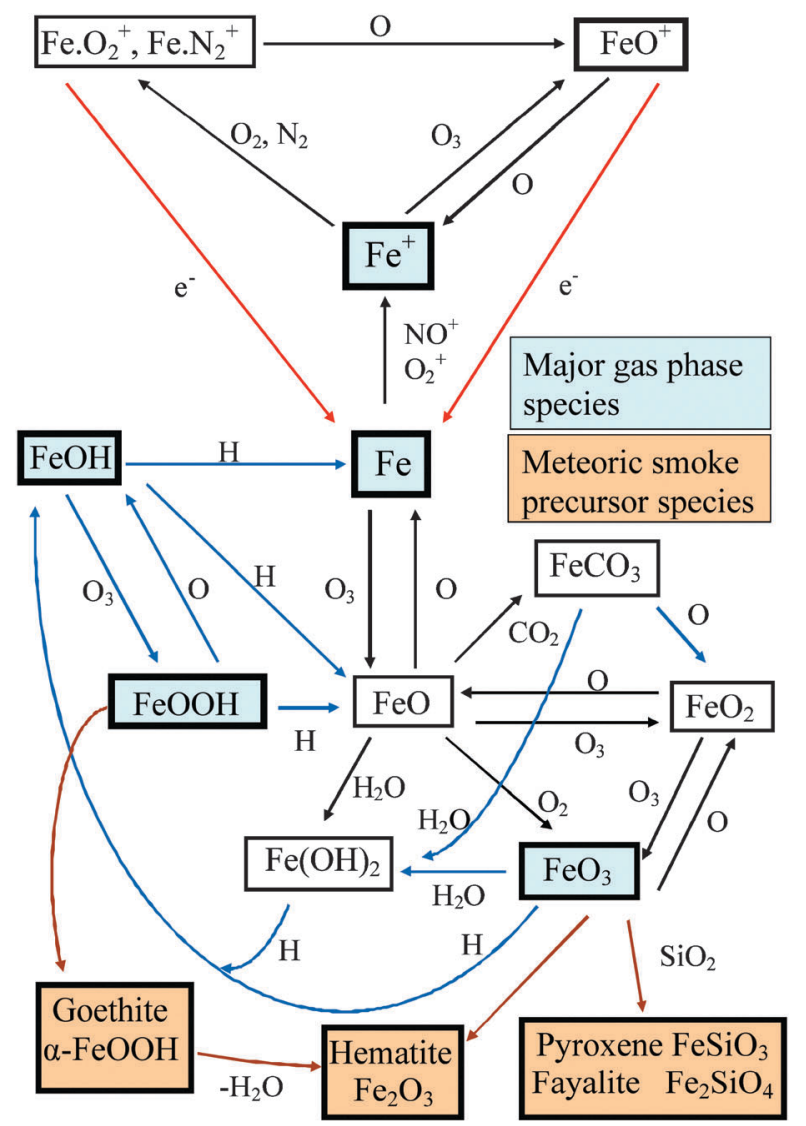

Fig. $5 \mathrm{Fe}$ chemistry in the MLT. Black arrows: reactions with measured rate coefficients; red, blue, brown arrows indicate reactions which need laboratory study (see text).
The rate coefficients for the reactions depicted with black arrows have all been measured. Above $95 \mathrm{~km}, \mathrm{Fe}^{+}$ions are produced by charge transfer with the lower $E$ region ions $\mathrm{NO}^{+}$ and $\mathrm{O}_{2}{ }^{+}$. Neutralisation of $\mathrm{Fe}^{+}$then occurs via reaction with $\mathrm{O}_{3}$ to form $\mathrm{FeO}^{+}$, or recombination with $\mathrm{O}_{2}$ to form $\mathrm{FeO}_{2}{ }^{+}$, producing molecular ions which can then undergo dissociative recombination (DR) with electrons to generate Fe (red arrows in Fig. 4).

Metallic ions, particularly $\mathrm{Fe}^{+}$and $\mathrm{Mg}^{+}$, are the major constituents of sporadic $E$ layers, thin layers of concentrated plasma which occur in the lower thermosphere $(95-130 \mathrm{~km}){ }^{48,49}$ Sporadic $E$ layers are important for radio communications, both enabling over-the-horizon radio propagation and attenuating ground-to-space communications. The chemical lifetimes (against neutralisation) of these metallic ions are controlled by the ion-molecule chemistry illustrated for the case of $\mathrm{Fe}^{+}$in Fig. 5. This shows that once molecular ions such as $\mathrm{FeO}^{+}$or $\mathrm{FeO}_{2}{ }^{+}$form, there is a competition between DR and conversion back to $\mathrm{Fe}^{+}$by reactions with atomic $\mathrm{O}$, which effectively slows down neutralisation. When a sporadic $E$ layer descends below $100 \mathrm{~km}$, the concentration of atomic $\mathrm{O}$ decreases markedly in relation to $\mathrm{O}_{3}, \mathrm{O}_{2}$ and $\mathrm{N}_{2}$. ${ }^{6}$ Thus, molecular ions form more quickly and are converted back to $\mathrm{Fe}^{+}$more slowly. The combined effect is to reduce the lifetime of $\mathrm{Fe}^{+}$ from days above $100 \mathrm{~km}$, to only minutes at $90 \mathrm{~km} .^{58}$

Recently, low-lying sporadic ion layers have been observed, using radio occultation from spacecraft, to occur around $90 \mathrm{~km}$ on Mars, ${ }^{59,60} 120 \mathrm{~km}$ on Venus ${ }^{61}$ and $550 \mathrm{~km}$ on Titan. ${ }^{62}$ The $\mathrm{CO}_{2}$ atmospheres of Mars and Venus pose a particular challenge to the existence of metallic ions, because they should form $\mathrm{CO}_{2}$-clusters very rapidly and undergo DR. In fact, it turns out that sporadic layers in the Martian atmosphere are most likely $\mathrm{Mg}^{+}$rather than $\mathrm{Fe}^{+}$, following a recent laboratory study ${ }^{63}$ which showed that atomic $\mathrm{O}$ reacts much more rapidly with molecular $\mathrm{Mg}$-containing ions to form $\mathrm{Mg}^{+}$, compared with their Fe-containing analogues. This very effectively slows down the neutralisation of $\mathrm{Mg}^{+}$in a $\mathrm{CO}_{2}$-rich atmosphere. Titan is interesting because ablation occurs over a much greater altitude range, as a result of its small atmospheric scale height. ${ }^{29}$ An important reason for carrying out comparative studies with these other atmospheres is that this provides a self-consistency check of the meteor input functions produced from the ZCM throughout the solar system.

Below $85 \mathrm{~km}$ in the terrestrial atmosphere, Fig. 5 shows that atomic $\mathrm{Fe}$ is oxidised in a series of reactions involving $\mathrm{O}_{3}, \mathrm{O}_{2}$, $\mathrm{CO}_{2}$ and $\mathrm{H}_{2} \mathrm{O}$ to form $\mathrm{FeO}_{3}, \mathrm{Fe}(\mathrm{OH})_{2}$ and $\mathrm{FeOH} .{ }^{64}$ The latter may also be oxidized by $\mathrm{O}_{3}$ to form $\mathrm{FeOOH}$ (which is the building block of the mineral goethite). The reaction kinetics (blue arrows in Fig. 5) and photochemistry of species such as $\mathrm{FeOH}, \mathrm{FeOOH}, \mathrm{FeO}_{3}$ with $\mathrm{H}$ need to be studied experimentally, because they are key to understanding how quickly the metal reservoir species are permanently removed. This is thought to happen through the polymerisation of these compounds together with $\mathrm{SiO}_{2}$ vapour in the mesosphere over several days (brown arrows in Fig. 5), forming nanometre-sized meteoric smoke particles (MSPs) which provide a permanent sink for gas-phase metallic compounds (see ST3). ${ }^{65}$

The chemistry in Fig. 5 was recently incorporated into a 1-D model of the MLT to study the behavior of the Fe layer over 

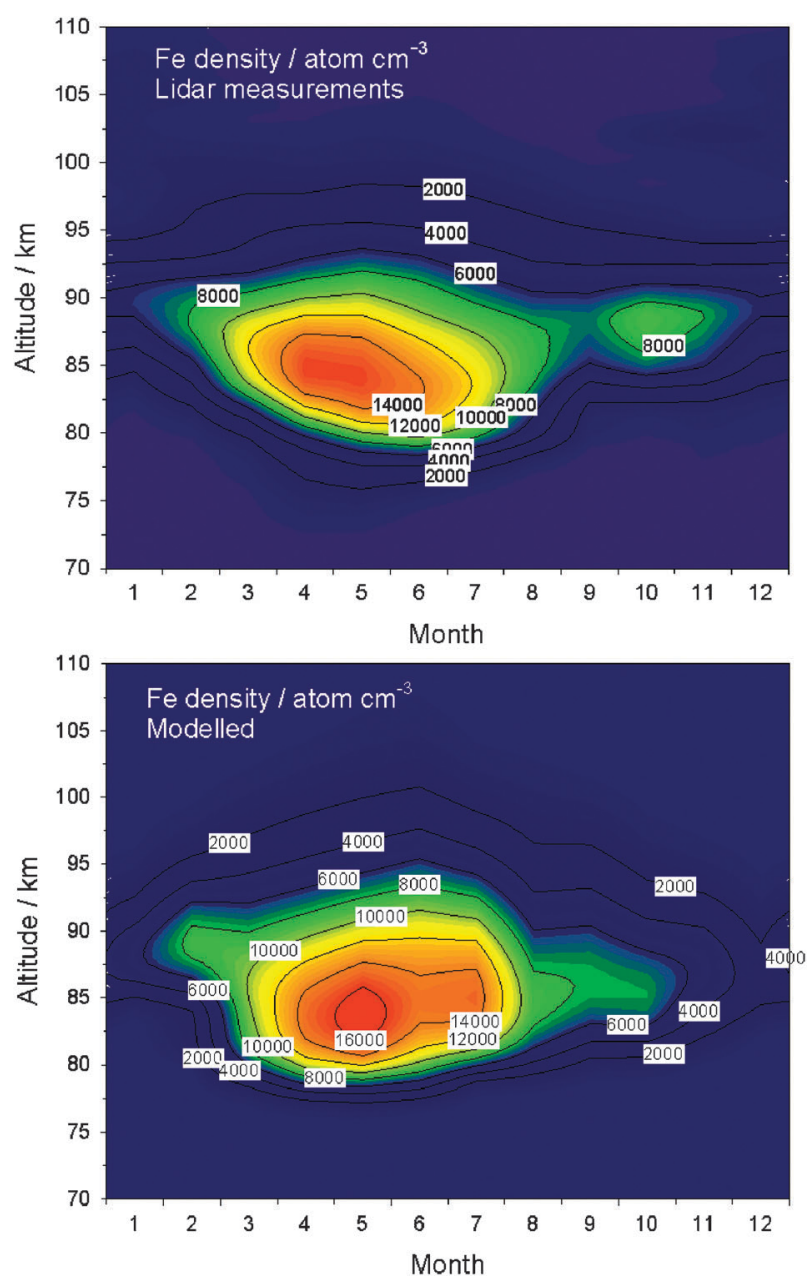

Fig. 6 Seasonal variation of the Fe layer vertical profile at Rothera (Antarctica). Top panel: lidar measurements. Bottom panel: model simulation with an $\mathrm{Fe}$ injection rate equivalent to an IDP input of $6 \mathrm{t} \mathrm{d}^{-1} \cdot 13$

Rothera (Antarctica), where a Fe lidar had been operated for two years. ${ }^{13}$ Fig. 6 (upper panel) illustrates the observed seasonal variation of the layer height profile. As in the case of Na layer (Fig. 4), the minimum occurs during the summer months when the MLT is cold and noctilucent clouds are present. The maximum in the Fe layer occurs in late autumn rather than mid-winter, because the MLT temperature and the meteor input function both maximize then. ${ }^{13}$ The lower panel of Fig. 6 shows that the model is able to capture this seasonal variation, as well as the correct height of the peak of the layer.

Strikingly, an IDP input of only $6 \mathrm{t} \mathrm{d}^{-1}$ was required for the model to produce the observed absolute Fe concentration. However, this depends crucially on the rate of vertical transport of the ablated Fe through the MLT to below $80 \mathrm{~km}$, where it is presumed to be permanently removed as MSPs. A previous modelling study of the $\mathrm{Na}$ layer ${ }^{12}$ showed that the size of the IDP input required to model the observed atomic $\mathrm{Na}$ layer correlates roughly linearly with the vertical eddy diffusion coefficient $\left(K_{\mathrm{zz}}\right)$. Since $K_{\mathrm{zz}}$ is itself a poorly known parameterisation of vertical transport, measurements of metal atom concentrations do not directly constrain the IDP input rate.
Four components of vertical transport in the MLT have been identified recently. ${ }^{66}$ These are: the residual mean circulation (downwards in winter, reverse in summer); turbulent (eddy) diffusion, produced by breaking gravity waves; downwards dynamical transport caused by dissipating gravity waves; and chemical transport, where wave action and irreversible chemical loss at a lower altitude (e.g. to form MSPs) produces a net flux. A high performance metal resonance lidar has been used to measure the $\mathrm{Na}$ atom density and vertical wind profiles simultaneously; the average of their product yields the vertical $\mathrm{Na}$ atom flux as a function of height. ${ }^{66}$ The annual-average downward $\mathrm{Na}$ flux measured at the Starfire Optical Range (New Mexico) corresponds to an IDP input of about $24 \mathrm{t} \mathrm{d}^{-1}$. Interestingly, this input is $\sim 4$ times higher than that needed for the 1-D simulation in Fig. 6, which only includes vertical transport by eddy diffusion. ${ }^{13}$ Dynamical and chemical transport appear to be much more important than turbulent transport, so that until these transport mechanisms are included in models it will not be possible to use the measured metal atom concentrations to constrain the IDP input (or at least the ablated input) reliably. Unfortunately, both dynamical and chemical transport are driven by relatively short period/wavelength gravity waves which cannot yet be resolved explicitly in general circulation models.

Nevertheless, the relative concentrations of the different meteoric metal atoms provide valuable information. Now that the relevant ion-molecule and neutral reactions of $\mathrm{Na}-\mathrm{Fe}-$, $\mathrm{Mg}$ - and $\mathrm{Ca}$-containing species have been studied in detail in the laboratory, $6,12,56,64,67-71$ the atmospheric chemistries of these metals can be reasonably well quantified in a model. This means that more robust conclusions can be drawn regarding the relative meteoric ablation rates of $\mathrm{Na}, \mathrm{Fe}, \mathrm{Mg}$ and $\mathrm{Ca}$ that are required to reproduce lidar measurements of the metals. In the case of $\mathrm{Na}$ and $\mathrm{Fe}$, modelling a set of lidar observations of both metals at South Pole showed that the $\mathrm{Fe}$ ablation rate, relative to that of $\mathrm{Na}$, needed to be reduced by a factor of $\sim 4 .^{72}$ That is, the $\mathrm{Fe}: \mathrm{Na}$ ablation rates need to be $\sim 4: 1$, compared to their chondritic ratios of $15: 1$. The $\mathrm{Mg}$ ablation rate needs to be decreased relative to that of $\mathrm{Na}$ by a factor of $\sim 5$, while Ca ablation rate needs to be decreased by a factor of $\sim 40 .{ }^{57}$ These relative ablation factors therefore increase as the element becomes more refractory. As discussed in ST1, significant differential ablation will occur if most of the incoming IDs are small and/or slow, i.e. in close to prograde orbits. Alternatively, the evaporation coefficients ${ }^{39}$ for the refractory elements in the Herz-Knudsen equation (eqn (III)) could be much less than unity.

However, this creates a potential difficulty. If there is a population of meteoroids that lose all their volatile elements ( $\mathrm{Na}$ and $\mathrm{K}$ ), but do not then ablate completely, this implies that the particles must have melted (diffusion of $\mathrm{Na}$ and $\mathrm{K}$ through the solid particles would be too slow to allow them to escape into the gas phase). If a particle of mass greater than $10^{-9} \mathrm{~g}$ survives atmospheric entry, then it should sediment rapidly to the earth's surface (within a day). Hence, there should be a fairly homogeneous scattering of once-molten IDPs at the surface. These particles are termed cosmic spherules, and can be identified in polar ice because they are close to perfectly spherical and glassy, having melted during atmospheric entry. 
The accretion rate of cosmic spherules has been measured by retrieving them from the bottom of an ice chamber used for a drinking water tank at the Scott-Amundsen base at South Pole. ${ }^{73}$ The flux and size distribution of 50-700 $\mu \mathrm{m}$ diameter particles, corresponding to particles in the mass range from 0.2 to $500 \mu \mathrm{g}$, were used in the study. This mass range covers the bulk of IDP particles (Fig. 2), so these cosmic spherules should provide a useful measure of the bulk of IDPs which underwent partial ablation. Furthermore, because the spherules sediment rapidly through the atmosphere, they are not subject to atmospheric circulation, as in the case of the much smaller MSPs (see ST 5). Thus, the flux measured at South Pole should be a good measure of the flux of unablated IDP material. This flux corresponds to a global input of $7.4 \pm 0.9 \mathrm{t} \mathrm{d}^{-1} .^{73}$

If the average meteoroid entry velocity peaks around $25 \mathrm{~km} \mathrm{~s}^{-1}$ based on radar measurements (see ST 1), then about $90 \%$ of the incoming mass should ablate. ${ }^{5,73}$ This would imply that the total IDP input was around $74 \mathrm{t} \mathrm{d}^{-1}$. However, that would not explain why a fraction of only $\sim 0.25$ of the incoming $\mathrm{Fe}$ and $\mathrm{Mg}$ ablated relative to $\mathrm{Na}$. Since these are the major meteoric constituents, the implication would be that the total IDP input is only around $7.4 /(1-0.25)=10 \mathrm{t} \mathrm{d}^{-1}$. That in turn would imply that the average entry velocity is less than $15 \mathrm{~km} \mathrm{~s}^{-1}$ i.e., most of the IDPs are in a prograde orbit, in accord with the $\mathrm{ZCM}^{1}$

\section{ST3. Formation and impact of MSPs in the upper mesosphere}

A measurement of the size distribution (or volume density) of MSPs in the middle mesosphere should provide another constraint on the IDP input. MSPs can be measured directly above $70 \mathrm{~km}$ by rocket-borne particle detectors. ${ }^{74-76}$ However, these detectors measure only those particles that are charged. Thus, the total MSP concentration is obtained by dividing the measured number by the estimated fraction of charged particles in the plasma. Because the plasma density in the $D$ region is in the region of $100-1000 \mathrm{~cm}^{-3}$, similar to the number density of MSPs, the modelled fraction of MSPs which are charged is sensitive to a number of poorly known parameters (e.g. electronparticle attachment rates, positive ion-charged particle recombination rates). ${ }^{74}$ In order to improve this situation, a new particle detector has recently been flown which contains a pulsed VUV lamp to photo-detach electrons from negatively charged particles (the ECOMA instrument). ${ }^{77}$ Importantly, instruments of this type could potentially measure the MSP volume density (the number of electrons on an MSP should scale with its volume), rather than the number density, once photo-detachment rates from MSP analogues have been measured in the laboratory. ${ }^{77}$ The total MSP volume density could then be related to the IDP input. It is worth noting that the MSP number density and size have also been estimated by analysing the backscatter signals from HPLA radars, ${ }^{78}$ although this is a less direct technique.

An important reason for studying MSPs in the mesosphere is their relation to noctilucent clouds (NLCs). These clouds were first reported in 1885, and have been growing brighter and spreading to lower latitudes through much of the last century, so that they appear to be a clear signal of climate change. ${ }^{79}$ NLCs occur between 80 and $86 \mathrm{~km}$, at high latitudes in the summer where the temperature falls below $150 \mathrm{~K}$ and $\mathrm{H}_{2} \mathrm{O}$ vapour, which is present at mixing ratios of only a few parts per million, is then able to form ice particles spontaneously. ${ }^{7}$ An important uncertainty in NLC research is the nature of the nuclei on which the ice particles grow. Understanding this is important because changes to the dominant meridional circulation in the mesosphere (which is driven by gravity waves from the lower atmosphere $^{6}$ ) may alter the supply of nuclei, which would then affect both the occurrence frequency and brightness of the clouds. Furthermore, the increasingly consistent estimates of ice cloud particle numbers obtained from lidar, radar and satellite observations ${ }^{7}$ can be linked back to the MSP number density and hence to the IDP input.

Electronic structure calculations have recently been used to demonstrate that the smallest MSPs which should act as ice nuclei are the metal silicate molecules $\mathrm{FeSiO}_{3}$ and $\mathrm{MgSiO}_{3}{ }^{80}$ This is because $\mathrm{MgSiO}_{3}$ and $\mathrm{FeSiO}_{3}$ have extremely large electric dipole moments of 12.2 and 9.5 Debye, respectively, so that $\mathrm{H}_{2} \mathrm{O}$ molecules bind to them with large negative free energies. The hydration thermodynamics indicate that ice nucleation should occur at a temperature around $140 \mathrm{~K}$ for a $\mathrm{H}_{2} \mathrm{O}$ mixing ratio of $4 \mathrm{ppm}$, typical of the polar summer mesosphere where NLCs form.

\section{ST4. MSPs in the lower mesosphere, stratosphere and upper troposphere}

Below $80 \mathrm{~km}$, ultrafine particles (diameter $<10 \mathrm{~nm}$ ) do not sediment rapidly. Instead, whole atmosphere circulation models predict that MSPs should be swept to the winter pole by the mean meridional circulation in the mesosphere before downward transport within the polar vortex to the lower stratosphere. ${ }^{81-83}$ Indeed, recent airborne measurements have revealed a 3-fold increase of the meteoritic content of stratospheric sulphate aerosol inside the winter Arctic vortex. ${ }^{84}$ During the months which MSPs spend in the mesosphere and upper stratosphere, the particles are likely to grow by agglomerative coagulation, which can be very rapid because of the long-range magnetic dipole forces between the Fe-containing particles. ${ }^{85}$ Models predict that the particles could grow to around $40 \mathrm{~nm}$ in radius by the time they reach the middle stratosphere around $30 \mathrm{~km} .^{81,82}$

An important constraint on the IDP input is the optical extinction caused by MSPs between about 40 and $75 \mathrm{~km}$. It has recently become possible to measure these small extinctions (as low as $10^{-8} \mathrm{~km}^{-1}$ ), using a visible/near-IR spectrometer on the Aeronomy of Ice in the Mesosphere (AIM) satellite. ${ }^{15}$ Extinction measurements indicate that the MSP composition is probably olivine $\left(\mathrm{Mg}_{2 x} \mathrm{Fe}_{2-2 x} \mathrm{SiO}_{4}, x=0.4\right)$. However, the refractive indices used for this study were for bulk crystalline minerals, whereas MSPs are nm-size (and likely amorphous) particles; very small particles often have quite different refractive indices. ${ }^{86}$ The particles are also likely to be chemically weathered by $\mathrm{H}_{2} \mathrm{O}$ and $\mathrm{H}_{2} \mathrm{SO}_{4}$ during the months they spend descending into the stratosphere; this will probably lead to hydroxide and sulphate groups on the particle surfaces which again may change their optical properties significantly. Measured refractive index data on realistic particles are needed to relate the observed atmospheric extinctions to 
the MSP volume densities, and hence through a general circulation model to the IDP input.

Metal-rich MSPs should readily remove acidic species (e.g. $\mathrm{H}_{2} \mathrm{SO}_{4}, \mathrm{HCl}, \mathrm{HNO}_{3}$ ) from the gas phase. This may explain the unexpected decrease of $\mathrm{H}_{2} \mathrm{SO}_{4}$ measured by mass spectrometry on balloons in the upper stratosphere. ${ }^{87-89}$ Indeed, a recent study ${ }^{83}$ using the UK Met Office's Unified Model has shown that the observed removal of $\mathrm{H}_{2} \mathrm{SO}_{4}$ could be explained if the uptake coefficient of $\mathrm{H}_{2} \mathrm{SO}_{4}$ on MSPs is greater than $10^{-2}$ (for an IDP input of around $20 \mathrm{t} \mathrm{d}^{-1}$ ). If the uptake coefficient of $\mathrm{H}_{2} \mathrm{SO}_{4}$ on MSP analogue particles could be determined in the future, this type of modelling exercise could be reversed to obtain the volumetric surface area of MSPs in the upper stratosphere, and hence the IDP input.

Airborne flights of an aerosol mass spectrometer in the mid-latitude lower stratosphere have shown that sulphate particles contain $\sim 0.75 \mathrm{wt} \%$ and $\sim 0.2 \mathrm{wt} \%$ of meteoric $\mathrm{Fe}$ and $\mathrm{Mg}$, respectively. ${ }^{14}$ These fractions are even higher inside the winter polar vortices. ${ }^{84}$ A recent laboratory study ${ }^{83}$ showed that amorphous $\mathrm{Fe}-\mathrm{Mg}$-silicate particles dissolve in concentrated $\mathrm{H}_{2} \mathrm{SO}_{4}$ solutions at temperatures down to $230 \mathrm{~K}$ (typical lower stratospheric temperatures) on a time scale of less than a week. In fact, the very high concentrations of $\mathrm{Fe}$ and $\mathrm{Mg}$ measured by the airborne mass spectrometer ${ }^{14}$ imply that these metals are mostly in the form of solid sulphate particles in the droplets. Solid particles can act as efficient heterogeneous nuclei; this may explain an earlier laboratory study ${ }^{90}$ which found that concentrated binary $\mathrm{H}_{2} \mathrm{SO}_{4}-\mathrm{H}_{2} \mathrm{O}$ solutions containing $\mathrm{FeSO}_{4}$ and $\mathrm{MgSO}_{4}$ freeze to form sulphuric acid tetrahydrate (SAT) between 12 and $20 \mathrm{~K}$ higher than supercooled pure solutions.

Explaining nitric acid trihydrate (NAT) formation from the tertiary $\mathrm{HNO}_{3}-\mathrm{H}_{2} \mathrm{SO}_{4}-\mathrm{H}_{2} \mathrm{O}$ system in the winter polar stratosphere has been a long-standing problem. Homogeneous nucleation of NAT is too slow to account for observed NAT particles in the polar vortex, ${ }^{91}$ and MSPs have therefore been proposed as likely heterogeneous nuclei. ${ }^{92}$ Although experiments have been performed with silica particles ${ }^{93}$ and ground-up meteorites, ${ }^{94}$ neither of these surrogates is representative of the amorphous, fractal-like nature of MSPs, ${ }^{65,85}$ so that the nucleating ability of realistic MSP analogues should be investigated.

MSPs could therefore modify the $\mathrm{O}_{3}$ depletion in the lower stratosphere resulting from chlorine activation on PSCs and de-nitrification. ${ }^{92}$ A detailed understanding of interactions between MSPs and stratospheric aerosols will be important for accurate predictions as the stratosphere cools over the next century. ${ }^{95}$ Also, in the context of proposed geo-engineering plans to increase the sulphate aerosol by pumping $\mathrm{SO}_{2}$ into the stratosphere (in order to increase the amount of solar radiation scattered directly back to space, thus counteract greenhouse gas-driven warming in the troposphere), ${ }^{96}$ a quantitative assessment should be made of the possible effects caused by meteoric debris.

\section{ST5. deposition to the surface}

The IDP input has been estimated from the accumulation of several different elements - Ir, Pt and super-paramagnetic
$\mathrm{Fe}$ - in ice cores. ${ }^{16-18,97,98}$ The deposition flux is determined by measuring the concentration of the element in the ice sample, and using the snow accumulation rate to obtain the flux. Ir, Pt and $\mathrm{Fe}$ also occur in terrestrial dust, so the terrestrial signal has to be carefully removed. In the case of $\mathrm{Ir}$ and $\mathrm{Pt}$, these elements are highly enriched in cosmic dust compared with crustal dust. ${ }^{18,98}$ This enrichment occurs because they are both siderophile elements, so that Ir and $\mathrm{Pt}$ present in the original solar nebula from which the Earth formed are now mostly dissolved in the molten iron core rather than in crustal rocks. Super-paramagnetic Fe occurs in Fe-rich particles trapped in the ice. Meteoric smoke particles are much smaller than terrestrial dust, so the MSPs can be selectively observed by cooling the ice sample to $77 \mathrm{~K}$ and then allowing it to warm. The MSPs (which are estimated to have radii between 3 and $9 \mathrm{~nm}{ }^{97}$ ) become mobile in the ice lattice at temperatures just above $100 \mathrm{~K}$, and their paramagnetism measured. Terrestrial dust exhibits its paramagnetism at much higher temperatures $(>200 \mathrm{~K}){ }^{16-17,97}$ Measurements in ice cores in central Greenland, ${ }^{17,18}$ and Vostok in the Eastern Antarctic highlands, ${ }^{16}$ reveal a consistent picture: the deposition rate in Greenland is $\sim 10$ times higher than at Vostok, and the Greenland estimate of the IDP input is at the high end of the range in Table $1\left(175-224 \mathrm{t} \mathrm{d}^{-1}\right)$. Similarly, the measured accumulation of $\operatorname{Ir}^{20}$ and $\mathrm{Os}^{19}$ in ocean-floor sediments indicates that the meteoric influx is around $240 \mathrm{t} \mathrm{d}^{-1}$.

How can these very high fluxes be reconciled with the estimates from within the atmosphere, which seem to be consistent with a flux of less than $50 \mathrm{t} \mathrm{d}^{-1}$ (Table 1)? Interpreting the ice core flux measurements requires understanding the transport of MSPs into the troposphere, and their subsequent deposition mechanisms. For instance, in the study ${ }^{18}$ of $\mathrm{Ir} / \mathrm{Pt}$ in the Greenland ice core it was postulated that MSPs descended from the mesosphere into the troposphere within the winter polar vortex, causing a localised concentration of MSPs at polar latitudes and hence the high deposition flux. However, a recent study ${ }^{83}$ of MSP transport using the Unified Model indicates that once MSPs reach the lower stratosphere in either polar vortex, they mostly enter the troposphere through mid-latitude tropopause folding. Dry deposition should then be reasonably uniform (within a factor of 2) over the entire earth's surface.

There are two problems with a uniform distribution of MSP deposition. First, it implies that the IDP flux really is much greater than $200 \mathrm{t} \mathrm{d}^{-1}$. Second, it does not explain why the deposition in Greenland is so much higher than Eastern Antarctica. The answer to the second point is that the snowfall rate in central Greenland is about 7 times greater than the Antarctic interior, implying that wet deposition is a more important removal mechanism for MSPs than dry deposition. ${ }^{97}$ Assuming that this is the case, the deposition map in Fig. 7 was generated by simply multiplying the precipitation rate by the MSP concentration in the lowest layer of the Unified Model, and then scaling to the Greenland ice core flux. Inspection of the figure shows that the deposition flux in central Greenland is about 7 times larger than in eastern Antarctica, in agreement with the measurements. However, the global IDP input is only reduced to $210 \mathrm{t} \mathrm{d}^{-1}$, so this serious discrepancy with the atmospheric estimates in Table 1 remains. 


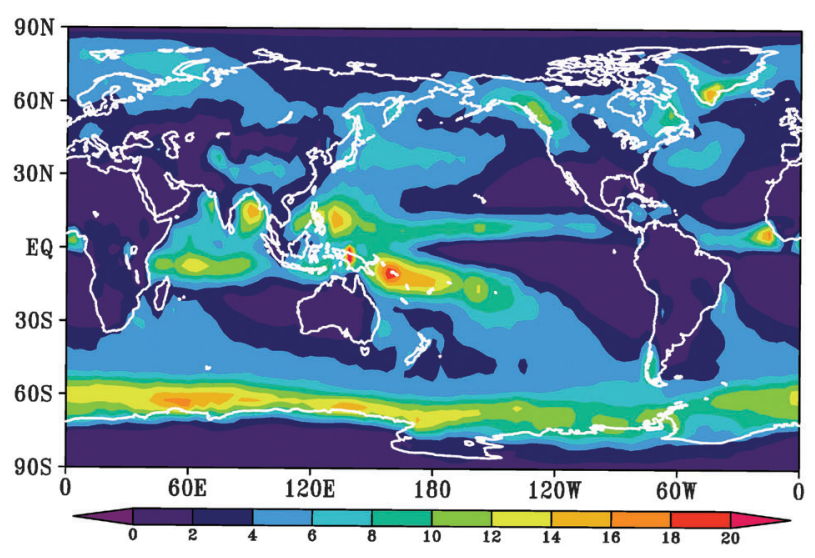

Fig. 7 Annual-averaged flux of MSPs to the earth's surface by wet deposition predicted by the Unified Model (Units: $10^{-11} \mathrm{~g} \mathrm{~cm}^{-2} \mathrm{~d}^{-1}$ ). Plot provided by S. Dhomse (University of Leeds).

Fig. 7 shows that the model predicts a large MSP deposition flux into the Southern Ocean around the coastal shelf of Antarctica (particularly in the Pacific sector), where the supply of bio-available iron to phytoplankton is limited. ${ }^{8}$ The estimated input from the Unified Model is $\sim 3 \mu \mathrm{mol} \mathrm{Fe} \mathrm{m}{ }^{-2} \mathrm{y}^{-1}$, compared with an Aeolian dust input of $\sim 30 \mu \mathrm{mol} \mathrm{Fe} \mathrm{m}{ }^{-2} \mathrm{y}^{-1} \cdot 99$ However, unlike continental mineral dust which has a low solubility (estimates vary from $<1$ to $10 \%$ ), the MSP Fe should be in the form of highly soluble $\mathrm{Fe}_{2} \mathrm{SO}_{4}$ after processing in the stratospheric sulphate layer (see ST4 above). Thus, the input of bio-available Fe from IDPs is likely to at least as large as (and perhaps an order of magnitude greater than) the Aeolian dust input. This could have significant climate implications because phytoplankton both draw down $\mathrm{CO}_{2}$ and produce dimethyl sulphide, which evades into the atmosphere and contributes to the formation of ultra-fine aerosol which may grow large enough to act as cloud condensation nuclei. ${ }^{100}$

\section{Conclusions}

The magnitude of the IDP input is uncertain by at least a factor of 10. This review has examined some of the different ways which can be used to determine this input, ranging from a solar system dust model to deposition at the Earth's surface. In each case, key uncertainties have been identified and future courses of action suggested to address them. To summarize, estimates of the IDP input fall into three ranges:

- 5-10 $\mathrm{t} \mathrm{d}^{-1}$ : this range is supported by: models of the metal layers in the MLT (although these models only include vertical transport by eddy diffusion); and the micrometeorite flux if the average entry velocity $<15 \mathrm{~km} \mathrm{~s}^{-1}$, which then also explains the differential ablation of $\mathrm{Ca}$ and $\mathrm{Fe}$ relative to $\mathrm{Na}$.

- $20-50 \mathrm{t} \mathrm{d}^{-1}$ : this range is supported by: the micrometeorite flux if the average entry velocity $>20 \mathrm{~km} \mathrm{~s}^{-1}$ (although then differential ablation is limited); MSP optical extinction in the middle atmosphere; the meteoritic content of stratospheric sulphate particles; and probably by MLT models if dynamical and chemical transport terms are included.

- 100-300 $\mathrm{t} \mathrm{d}^{-1}$ : this range is supported by spaceborne IDP detection (the LDEF experiment), and by the ZCM, although in both cases the estimates are reduced into the middle range if constrained by meteor radar measurements of entry velocity; the high range is also supported by surface deposition measurements, though there is uncertainty concerning transport into the troposphere and deposition mechanisms.

Finally, it is worth emphasising two points. First, the ablation of cosmic dust plays a number of significant roles throughout the atmosphere from the thermosphere to the surface, and some of these may be even more important if the IDP input is close to the upper end of current estimates. Second, even if the IDP input is close to the lower end of the range, this indicates that there are important gaps in understanding the evolution of dust in the solar system, and the transport processes coupling the different regions of the atmosphere.

\section{Acronyms}

CABMOD Chemical Ablation Model

DR dissociative recombination (with electrons)

HPLA high performance large aperture (radar)

IDP interplanetary dust particle

LDEF Long Duration Exposure Facility

MIF meteoric input function

MLT mesosphere/lower thermosphere

MSP meteoric smoke particle

NAT nitric acid trihydrate

NLC noctilucent cloud

PSC polar stratospheric cloud

SAT sulphuric acid tetrahydrate

ST Science Topic

UM Unified Model

ZCM Zodiacal Cloud Model.

\section{Acknowledgements}

This study was supported by project number 291332 (CODITA Cosmic Dust in the Terrestrial Atmosphere) from the European Research Council. The author thanks Dr Sandip Dhomse and Professor Martyn Chipperfield for providing unpublished data from the Unified Model.

\section{Notes and references}

1 D. Nesvorny, P. Jenniskens, H. F. Levison, W. F. Bottke, D. Vokrouhlicky and M. Gounelle, Astrophys. J., 2009, 713, 816-836.

2 I. P. Williams, in Meteors in the earth's atmosphere, ed. E. Murad and I. P. WIlliams, Cambridge University Press, Cambridge, 2002, pp. 2-32.

3 Z. Ceplecha, J. Borovicka, W. G. Elford, D. O. Revelle, R. L. Hawkes, V. Porubcan and M. Simek, Space Sci. Rev., 1998, 84, 327-471.

4 P. Jenniskens, Earth Planets Space, 1998, 50, 555-567.

5 T. Vondrak, J. M. C. Plane, S. Broadley and D. Janches, Atmos. Chem. Phys., 2008, 8, 7015-7031.

6 J. M. C. Plane, Chem. Rev., 2003, 103, 4963-4984

7 M. Rapp and G. E. Thomas, J. Atmos. Sol.-Terr. Phys., 2006, 68, 715-744.

8 K. S. Johnson, Global Biogeochem. Cycles, 2001, 15, 61-63.

9 S. G. Love and D. E. Brownlee, Science, 1993, 262, 550-553.

10 J. D. Mathews, D. Janches, D. D. Meisel and Q. H. Zhou, Geophys. Res. Lett., 2001, 28, 1929-1932.

11 D. W. Hughes, in Cosmic Dust, ed. J. A. M. McDonnell, Wiley, London, 1978, pp. 123-185. 
12 J. M. C. Plane, Atmos. Chem. Phys., 2004, 4, 627-638.

13 C. S. Gardner, X. Z. Chu, P. J. Espy, J. M. C. Plane, D. R. Marsh and D. Janches, J. Geophys. Res., 2011, 116, D02304.

14 D. J. Cziczo, D. S. Thomson and D. M. Murphy, Science, 2001, 291, 1772-1775.

15 M. E. Hervig, L. L. Gordley, L. E. Deaver, D. E. Siskind, M. H. Stevens, J. M. Russell, S. M. Bailey, L. Megner and C. G. Bardeen, Geophys. Res. Lett., 2009, 36, L18805.

16 L. Lanci, D. V. Kent and P. E. Biscaye, Geophys. Res. Lett., 2007, 34, L10803.

17 L. Lanci and D. V. Kent, Geophys. Res. Lett., 2006, 33, L13308.

18 P. Gabrielli, C. Barbante, J. M. C. Plane, A. Varga, S. Hong, G. Cozzi, V. Gaspari, F. A. M. Planchon, W. Cairns, C. Ferrari, P. Crutzen, P. Cescon and C. F. Boutron, Nature, 2004, 432, 1011-1014.

19 B. Peucker-Ehrenbrink, Geochim. Cosmochim. Acta, 1996, 60, 3187-3196.

20 J. T. Wasson and F. T. Kyte, Geophys. Res. Lett., 1987, 14, 779-783.

21 G. J. Flynn, in Meteors in the earth's atmosphere, ed. E. Murad and I. P. WIlliams, Cambridge University Press, Cambridge, 2002.

22 W. J. Baggaley, in Meteors in the earth's atmosphere, ed. E. Murad and I. P. Williams, Cambridge University Press, Cambridge, 2002, pp. 123-148.

23 D. Janches, J. D. Mathews, D. D. Meisel and Q. H. Zhou, Icarus, 2000, 145, 53-63.

24 A. Pellinen-Wannberg and G. Wannberg, J. Geophys. Res., 1994, 99, 11379-11390.

25 S. Close, S. Hunt, M. Minardi and F. McKeen, Radio Sci., 2000, 35, 1233-1240.

26 S. Close, P. Brown, M. Campbell-Brown, M. Oppenheim and P. Colestock, Icarus, 2007, 186, 547-556.

27 D. Janches, S. Close and J. T. Fentzke, Icarus, 2008, 193, $105-111$.

28 D. Janches, C. J. Heinselman, J. L. Chau, A. Chandran and R. Woodman, J. Geophys. Res., 2006, 111, A07317.

29 J. G. Molina-Cuberos, J. J. Lopez-Moreno and F. Arnold, Space Sci. Rev., 2008, 137, 175-191.

30 S. G. Love and D. E. Brownlee, Icarus, 1991, 89, 26-43.

31 O. Kalashnikova, M. Horanyi, G. E. Thomas and O. B. Toon, Geophys. Res. Lett., 2000, 27, 3293-3296.

32 D. M. Hunten, R. P. Turco and O. B. Toon, J. Atmos. Sci., 1980, 37, 1342-1357.

33 F. J. M. Rietmeijer, Meteorit. Planet. Sci., 2000, 35, 1025-1042.

34 F. J. M. Rietmeijer, in Meteors in the earth's atmosphere, ed. E. Murad and I. P. Williams, Cambridge University Press, Cambridge, 2002, pp. 215-245.

35 E. Anders and M. Ebihara, Geochim. Cosmochim. Acta, 1982, 46, $2363-2380$

36 J. Jones and T. R. Kaiser, Mon. Not. R. Astr. Soc., 1966, 133, 411-420.

37 J. B. Fegley and A. G. W. Cameron, Earth Planet. Sci. Lett., 1987, 82, 207-222.

38 D. Janches, L. P. Dyrud, S. L. Broadley and J. M. C. Plane, Geophys. Res. Lett., 2009, 36, L06101.

39 C. Alexander, Meteorit. Planet. Sci., 2002, 37, 245-256.

40 D. Nesvorny, D. Janches, D. Vokrouhlicky, P. Pokorny, W. F. Bottke and P. Jenniskens, Astrophys. J., 2011, 743, 129.

41 J. M. C. Plane, Int. Rev. Phys. Chem., 1991, 10, 55-106.

42 R. J. States and C. S. Gardner, J. Atmos. Sci., 2000, 57, 66-77.

43 C. S. Gardner and M. J. Taylor, J. Geophys. Res., 1998, 103, 6427-6437.

44 V. Eska, J. Hoffner and U. von Zahn, J. Geophys. Res., 1998, 103, 29207-29214.

45 F. J. Lübken, J. Höffner, T. P. Viehl, B. Kaifler and R. J. Morris, Geophys. Res. Lett., 2011, 38, L24806.

46 X. Z. Chu, W. L. Pan, G. C. Papen, C. S. Gardner and J. A. Gelbwachs, Appl. Opt., 2002, 41, 4400-4410.

47 B. R. Clemesha, D. M. Simonich, H. Takahashi, S. M. L. Melo and J. M. C. Plane, J. Geophys. Res., 1995, 100, 18909-18916.

48 E. Kopp, J. Geophys. Res., 1997, 102, 9667-9674.

49 J. M. Grebowsky and A. C. Aikin, in Meteors in the earth's atmosphere, ed. E. Murad and I. P. Williams, Cambridge University Press, Cambridge, 2002, pp. 189-214.
50 J. A. Gardner, E. Murad, R. A. Viereck, D. J. Knecht, C. P. Pike and A. L. Broadfoot, Adv. Space Res., 1998, 21, 867-870.

51 Z. Y. Fan, J. M. C. Plane, J. Gumbel, J. Stegman and E. J. Llewellyn, Atmos. Chem. Phys., 2007, 7, 4107-4115.

52 J. Correira, A. C. Aikin, J. M. Grebowsky, W. D. Pesnell and J. P. Burrows, Geophys. Res. Lett., 2008, 35, L06103.

53 M. Scharringhausen, A. C. Aikin, J. P. Burrows and M. Sinnhuber, J. Geophys. Res., 2008, 113, D13303.

54 J. M. C. Plane, B. J. Murray, X. Z. Chu and C. S. Gardner, Science, 2004, 304, 426-428.

55 S. Raizada, M. Rapp, F. J. Lübken, J. Höffner, M. Zecha and J. M. C. Plane, J. Geophys. Res., 2007, 112, D08307.

56 J. M. C. Plane, in Meteors in the earth's atmosphere, ed. E. Murad and I. P. Williams, Cambridge University Press, Cambridge, 2002, pp. 289-309.

57 M. Gerding, M. Alpers, U. von Zahn, R. J. Rollason and J. M. C. Plane, J. Geophys. Res., 2000, 105, 27131-27146.

58 K. R. S. Woodcock, T. Vondrak, S. R. Meech and J. M. C. Plane, Phys. Chem. Chem. Phys., 2006, 8, 1812-1821.

59 M. Pätzold, S. Tellman, B. Häusler, D. Hinson, R. Schaa and G. L. Tyler, Science, 2005, 310, 837-839.

60 P. Withers, M. Mendillo, D. P. Hinson and K. Cahoy, J. Geophys. Res., 2008, 113, A12314.

61 M. Pätzold, S. Tellmann, B. Häusler, M. K. Bird, G. L. Tyler, A. A. Christou and P. Withers, Geophys. Res. Lett., 2009, 36, L05203.

62 A. J. Kliore, A. F. Nagy, E. A. Marouf, R. G. French, F. M. Flasar, N. J. Rappaport, A. Anabttawi, S. W. Asmar, D. S. Kahann, E. Barbinis, G. L. Goltz, D. U. Fleischman and D. J. Rochblatt, J. Geophys. Res., 2008, 113, A09317.

63 C. L. Whalley and J. M. C. Plane, Faraday Discuss., 2010, 147, 349-368.

64 D. E. Self and J. M. C. Plane, Phys. Chem. Chem. Phys., 2003, 5, $1407-1418$

65 R. W. Saunders and J. M. C. Plane, Icarus, 2011, 212, 373-382.

66 C. S. Gardner and A. Z. Liu, J. Geophys. Res., 2010, 115, D20302.

67 S. L. Broadley and J. M. C. Plane, Phys. Chem. Chem. Phys., 2010, 12, 9095-9107.

68 S. L. Broadley, T. Vondrak and J. M. C. Plane, Phys. Chem. Chem. Phys., 2007, 9, 4357-4369.

69 S. L. Broadley, T. Vondrak, T. G. Wright and J. M. C. Plane, Phys. Chem. Chem. Phys., 2008, 10, 5287-5298.

70 C. L. Whalley, J. C. Gomez Martin, T. G. Wright and J. M. C. Plane, Phys. Chem. Chem. Phys., 2011, 13, 6352-6364.

71 J. M. C. Plane and C. L. Whalley, J. Phys. Chem. A, 2012, DOI: $10.1021 / \mathrm{jp} 211526 \mathrm{~h}$.

72 C. S. Gardner, J. M. C. Plane, W. L. Pan, T. Vondrak, B. J. Murray and X. Z. Chu, J. Geophys. Res., 2005, 110, D1030210.

73 S. Taylor, J. H. Lever and R. P. Harvey, Nature, 1998, 392, 899-903.

74 M. Rapp, I. Strelnikova and J. Gumbel, Adv. Space Res., 2007, 40, 809-817.

75 K. A. Lynch, L. J. Gelinas, M. C. Kelley, R. L. Collins, M. Widholm, D. Rau, E. MacDonald, Y. Liu, J. Ulwick and P. Mace, J. Geophys. Res., 2005, 110, A03302.

76 L. J. Gelinas, K. A. Lynch, M. C. Kelley, R. L. Collins, M. Widholm, E. MacDonald, J. Ulwick and P. Mace, J. Geophys. Res., 2005, 110, A01310.

77 M. Rapp, I. Strelnikova, B. Strelnikov, P. Hoffmann, M. Friedrich, J. Gumbel, L. Megner, U. P. Hoppe, S. Robertson, S. Knappmiller, M. Wolff and D. R. Marsh, J. Geophys. Res., 2010, 115, D00I16.

78 J. T. Fentzke, D. Janches, I. Strelnikova and M. Rapp, J. Atmos. Sol.-Terr. Phys., 2009, 71, 1982-1991.

79 E. P. Shettle, M. T. DeLand, G. E. Thomas and J. J. Olivero, Geophys. Res. Lett., 2009, 36, L02803.

80 J. M. C. Plane, J. Atmos. Sol.-Terr. Phys., 2011, 73, 2192-2200.

81 C. G. Bardeen, O. B. Toon, E. J. Jensen, D. R. Marsh and V. L. Harvey, J. Geophys. Res., 2008, 113, D17202.

82 L. Megner, D. E. Siskind, M. Rapp and J. Gumbel, J. Geophys. Res., 2008, 113, D03202.

83 R. W. Saunders, S. Dhomse, W. S. Tian, M. P. Chipperfield and J. M. C. Plane, Atmos. Chem. Phys., 2012, 12, 4387-4398.

84 J. Curtius, R. Weigel, H. J. Vossing, H. Wernli, A. Werner, C. M. Volk, P. Konopka, M. Krebsbach, C. Schiller, 
A. Roiger, H. Schlager, V. Dreiling and S. Borrmann, Atmos. Chem. Phys., 2005, 5, 3053-3069.

85 R. W. Saunders and J. M. C. Plane, J. Atmos. Sol--Terr. Phys., 2006, 68, 2182-2202.

86 D. R. Huffman, Adv. Phys., 1977, 26, 129-230.

87 M. J. Mills, O. B. Toon, V. Vaida, P. E. Hintze, H. G. Kjaergaard, D. P. Schofield and T. W. Robinson, J. Geophys. Res., 2005, 110, D08201.

88 E. Arijs, D. Nevejans, J. Ingels and P. Frederick, J. Geophys. Res., 1985, 90, 5891-5896.

89 F. Arnold, R. Fabian and W. Joos, Geophys. Res. Lett., 1981, 8, 293-296.

90 M. E. Wise, S. D. Brooks, R. M. Garland, D. J. Cziczo, S. T. Martin and M. A. Tolbert, J. Geophys. Res., 2003, 108, 4434.

91 D. A. Knopf, J. Phys. Chem. A, 2006, 110, 5745-5750.

92 C. Voigt, H. Schlager, B. P. Luo, A. D. Dornbrack, A. Roiger, P. Stock, J. Curtius, H. Vossing, S. Borrmann, S. Davies, P. Konopka, C. Schiller, G. Shur and T. Peter, Atmos. Chem. Phys., 2005, 5, 1371-1380.
93 A. Bogdan, M. J. Molina, M. Kulmala, A. R. MacKenzie and A. Laaksonen, J. Geophys. Res., 2003, 108, 4302.

94 U. M. Biermann, T. Presper, T. Koop, J. Mossinger, P. J. Crutzen and T. Peter, Geophys. Res. Lett., 1996, 23, 1693-1696.

95 Scientific Assessment of Ozone Depletion: 2010, WMO/UNEP, Geneva, 2011.

96 S. Tilmes, R. Muller and R. Salawitch, Science, 2008, 320, $1201-1204$

97 L. Lanci, B. Delmonte, D. V. Kent, V. Maggi, P. E. Biscaye and J. R. Petit, Quat. Sci. Rev., 2012, 33, 20-31.

98 P. Gabrielli, J. M. C. Plane, C. F. Boutron, S. M. Hong, G. Cozzi, P. Cescon, C. Ferrari, P. J. Crutzen, J. R. Petit, V. Y. Lipenkov and C. Barbante, Earth Planet. Sci. Lett., 2006, 250, 459-469.

99 C. Lancelot, A. de Montety, H. Goosse, S. Becquevort, V. Schoemann, B. Pasquer and M. Vancoppenolle, Biogeosciences, 2009, 6, 2861-2878.

100 A. J. Watson, D. C. E. Bakker, A. J. Ridgwell, P. W. Boyd and C. S. Law, Nature, 2000, 407, 730-733. 